\title{
Laboratory Modeling of Meteorite Impact Craters by Z-pinch Plasma
}

\author{
C. J. Ransom*
}

Vemasat Research Institute, 401 Mill Valley, Colleyville, TX 76034, USA

\begin{abstract}
Desai, et al. [1] simulated microparticle lunar impact craters using laser impacts. They produced crater diameters of several hundred $\mu \mathrm{m}$ in Al. Ford [2] made observations about lunar craters simulated by spark-machining on metal. These were also very small scale craters. This work expands the size of simulated impact craters from their sub-millimeter craters to craters over a centimeter and expands the type of crater material from metals to substances more likely to be found in large amounts on the surfaces of moons, asteroids and planets. The results support Desai's and Ford's suggestion that these analogs can contribute to the investigation of planetary events.
\end{abstract}

Keywords: Arc discharge, complex craters, crater modeling, plasma produced craters, meteorite impact, spheres.

\section{INTRODUCTION}

Laboratory modeling of meteorite impact craters has been done recently by Desai et al. [1] and earlier in the $20^{\text {th }}$ century by Ford [2]. Based on their $\mu \mathrm{m}$ diameter crater results, Desai wrote "it seems that there is a universal scaling law governing crater formation."

Dietz suggested that a lightning bolt, which is basically a $\mathrm{Z}$ - pinch plasma, i.e. the current is in the $\mathrm{z}$ direction in a cylindrical coordinate system and the magnetic field azimuthal, might create shocked minerals near craters in a manner similar to that thought to occur from meteorite impacts [3]. Although Dietz mentioned only terrestrial lightning scale discharges, Alfvén indicated that laboratory results can be extrapolated over twenty orders of magnitude to include effects seen in deep space [4]. Peratt noted that experimental plasma effects have been shown to be scalable over fourteen orders of magnitude [5]. Others have also noted that laboratory plasma experiments may be scaled to astrophysical phenomena [6].

Several years after Dietz's paper, Ford used a spark-machining apparatus and demonstrated similarities between laboratory craters and lunar craters [2]. This similarity was based in part on characteristics of the crater itself and in part on the observed distribution of craters, for example in crater chains and in the tendency for small craters to be found centered on the rims of larger craters. Both Desai and Ford produced craters in metal. I expanded that work using materials that are more likely analogs of planetary, lunar and asteroid surfaces. Like the previous investigators, I found that many visible characteristics of craters can be duplicated using plasma discharges. These results support the opinion that Desai's and Ford's suggestion is worth further investigation.

The initial work centered on visible characteristics of craters. Morphological characteristics that could be observed

*Address correspondence to this author at the Vemasat Research Institute, 401 Mill Valley, Colleyville, TX 76034, USA; Tel: 817581 2822;

E-mail: csubj@yahoo.com in picture images of laboratory craters were compared with morphological characteristics that could be observed in picture images of craters on various planets, moons, and asteroids. One characteristic was spherules sitting in a crater or sitting on the surface of a material. One type of spherule is made from hematite and is similar to those found on Mars. This work was reported at the April 2005 meeting of the American Physical Society [7]. The hematite results and other types of plasma generated spherules were described in a later paper [8]. Additional surface features created in the plasma laboratory resemble other features found on the surfaces of other Solar System bodies. These features included craters with rims, rimless craters, craters with dome-like appearing structures, multi-ring craters, canyons and radial patterns of surface disturbance.

Simon A. Stewart described findings about a well-preserved multi-ring crater found in the North Sea. He said, "How these rings form is right to the cutting edge of the research aspect". "It's not something that there's an accepted model for..." [9]. Modeling of other features is also not well developed. Herrick and Lyons wrote, "Complex impact craters, craters with such features as a flat floor, a central peak, and wall terraces, have never been created in common geologic materials in the lab or with large explosions" [10]. The fact that many of the characteristics mentioned by Herrick are produced in craters created by plasma methods supports the suggestion that this modeling field is worthy of additional investigation.

Mackey and Barlow presented what they referred to as a "7-point numeric scale to estimate the degree of degradation for craters [11]." The scale numbers 1.0 and 2.0 designated old craters described as rimless craters with a flat floor and no ejecta blanket. These definitions imply an assumption that all rimless craters were formed as craters with rims that were later eliminated by weathering.

Craddock noted craters on Mars are in widely different states of preservation [12]. This condition is assumed to be a function of age. Early suggestions were that the erosion process was caused by winds on Mars. Craddock noted that later research indicates that only a combination of fluvial 


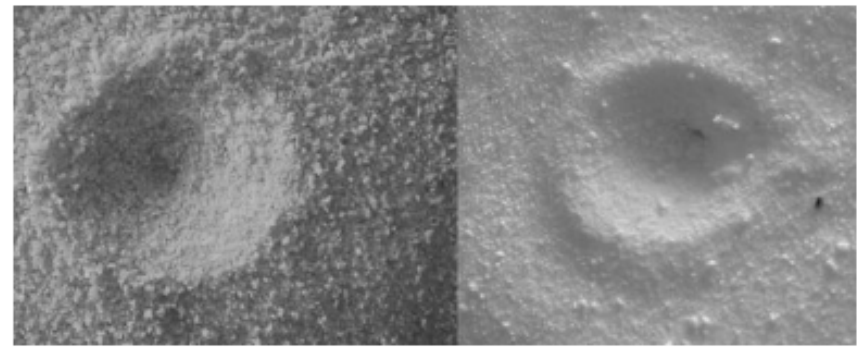

Fig. (1). Impact crater made in laboratory and plasma discharge crater made in laboratory.



Fig. (2). NASA picture of Bowl crater on Moon.

processes is capable of explaining the styles of crater morphology, the timing of modification, and the estimated amount of erosion for Mars. Neither of the previous two papers treats the case of craters originating as rimless.

Lohse et al. comment that there is abundant information from remote observations of craters on surfaces of bodies outside Earth and even on Earth; however, they note that direct observation of the process is almost impossible [13].

Large meteorites creating impact craters have never been observed; moreover, some common features of what are thought to be impact craters have not been reproduced in laboratory experiments. Therefore, Lohse et al. developed a scaled down approach that would reasonably duplicate the large scale impact process. A similar approach was used with the plasma generated craters.

In the case of plasmas, the processes are the same for orders of magnitude changes in the plasma. As did Desai's and Ford's laser and electrical machining results, the plasma craters described herein reproduce morphological features but tests were done with materials that more closely resemble the surface materials of various Solar System bodies.

\section{EXPERIMENTAL ARRANGEMENT}

Plasmas were created in a container with a discharge probe that could be moved in the vertical direction between experiments. The vertical distance from the probe to the sample could be set at $1 \mathrm{~cm}$ to $30 \mathrm{~cm}$. The probe was also moveable along a horizontal path of $10 \mathrm{~cm}$ during an experiment. The probe could move plus or minus $1 \mathrm{~cm}$ perpendicular to the horizontal path. Some tests were run using ac and others using dc. Discharge durations for experiments not using pulsed discharges were between 1 second and 20 seconds.

Samples were placed on metal plates that could be switched in dc experiments to act as the cathode or the anode. The sample containers were either metal trays, thin nonconducting trays, or non-conducting trays that used a conductor at the edge. Samples were generally between $4 \mathrm{~mm}$ and $12 \mathrm{~mm}$ in depth. We used powders and solids. Because it is difficult to make a uniformly smooth surface for each test, pictures were taken of the sample surface before and after a test.

Most plasma discharges were created with a 12,000 volt 120 ma supply that could be run with a voltage doubler. Smaller voltage supplies and a 100,000 volt micro amp discharge coil were used to develop a wide variation of plasmas.

\section{EXPERIMENTAL RESULTS}

An extensive range of features was found with a wide range of plasma and sample conditions. This paper addresses a small subset of the experiments. The tests considered here were run with dry samples.

The samples included solid sandstone, various sandy or powdered materials, and mixtures of materials that were added to water and then dried.

Craters were formed with features similar to craters found on planets, moons and asteroids. Features included craters with rims, rimless craters with debris in the adjacent area, rimless craters with no debris nearby, nearly rimless craters with debris adjacent to the crater, craters with spherules, craters without spherules, spherules without craters, craters with flat bottoms, multi-ringed craters, craters that resembled canyons, and rilles. The vast majority of the plasma formed craters were circular although occasionally the plasma discharge produced noncircular craters. This is consistent with Ford's $\mu \mathrm{m}$ results.

An impact crater made in the laboratory (Fig. 1 left), a plasma crater made in the laboratory (Fig. 1 right), and a crater on the Moon (Fig. 2) all have similar features. The right laboratory crater in Fig. (1) is about $20 \mathrm{~mm}$ in diameter and about $4 \mathrm{~mm}$ deep at the center. There is even a ridge extending to the right in the plasma crater and lunar crater.

A spherule in the bottom of a crater is, under certain conditions, a common feature of plasma-discharge generated craters. Details about spherules and craters from plasma discharges are presented in other papers $[7,8]$.

The spherule feature was not mentioned by Lohse. That is probably because they did not observe that feature in their experiments. That feature may be difficult to create by an impact.

Lohse mentioned a crown-like "splash" [13]. He used a high speed camera to capture the series of events. During the impact experiment, the crown dissipates as the process evolves. In the plasma experiment, a crown-like feature is noted above some craters. In the plasma case, the crown can freeze into place, as depicted in Fig (3). The dark ring in Fig. (3) is about $20 \mathrm{~mm}$ in diameter. The depth is a few $\mathrm{mm}$ below the flat area. 


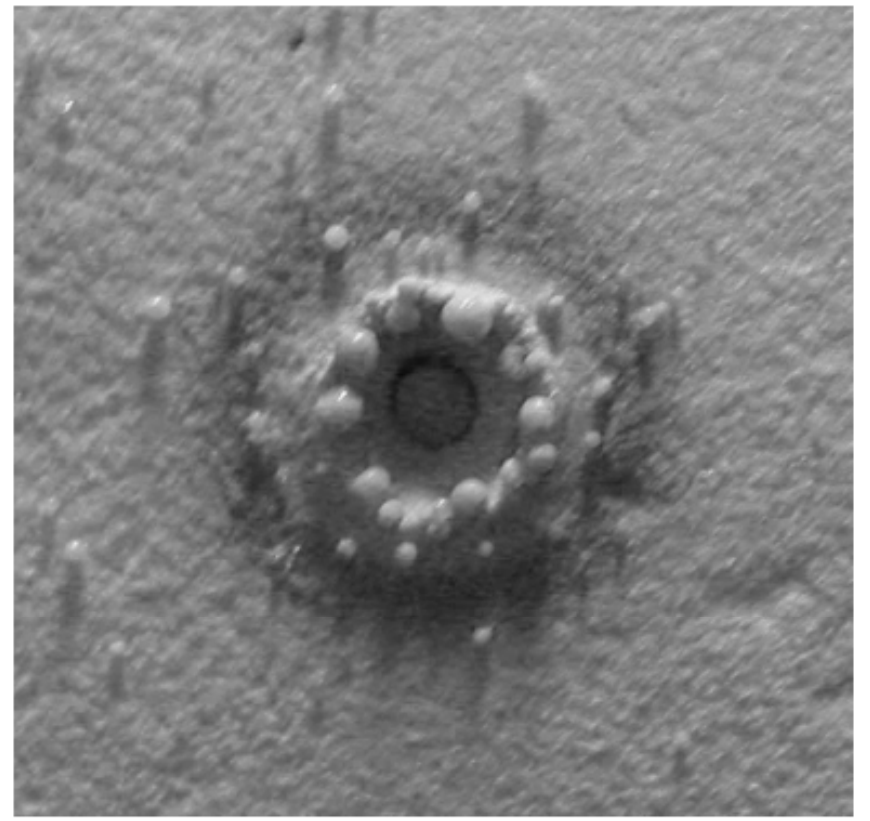

Fig. (3). Crown-like feature with spherules around crater from plasma discharge.

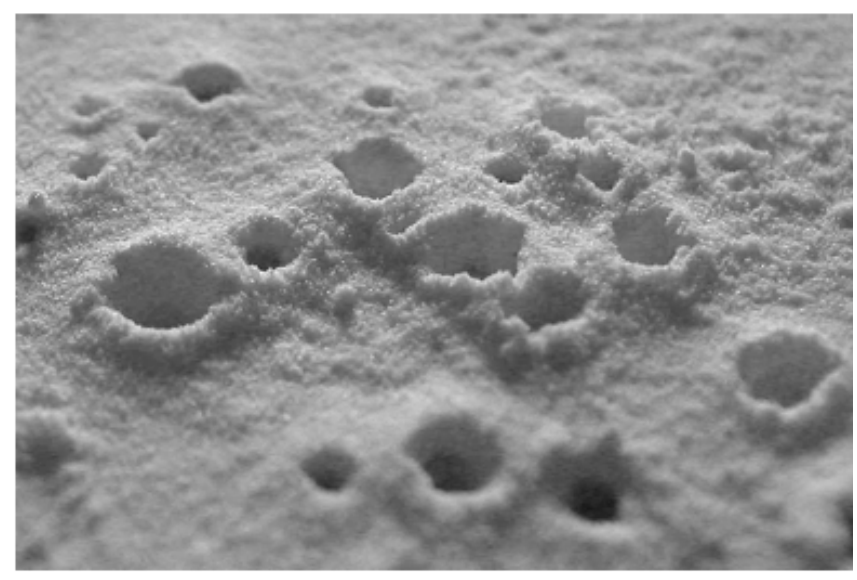

Fig. (4). Crater field with some craters having adjacent walls.

Individual craters are interesting, but so are groups of craters. Some of these craters (Fig. 4) even have adjacent walls as seen in numerous crater sets found on planetary surfaces. Adjacent craters with little explosive disturbance are often seen in natural crater fields. The craters in Fig. (4) are approximately 2 to $6 \mathrm{~mm}$ in diameter and 3 to $4 \mathrm{~mm}$ deep.

Following are pictures of additional crater features listed earlier.

Fig. (5) shows a circular rimless crater made by plasma discharge. The crater was made in an $8 \mathrm{~mm}$ layer of caliche on top of a $4 \mathrm{~mm}$ thick piece of Arkansas sandstone. The small hole near the center of the floor of Fig. (5) is where the discharge went through the sandstone to the anode. The crater is about $19 \mathrm{~mm}$ in diameter. The debris from the rimless circular craters was expelled from the holes and deposited at a relatively large distance in all directions from the craters.

There are circular rimless craters on Mars (Fig. 6). One crater is located east of the Hesperia Planitia region. Some

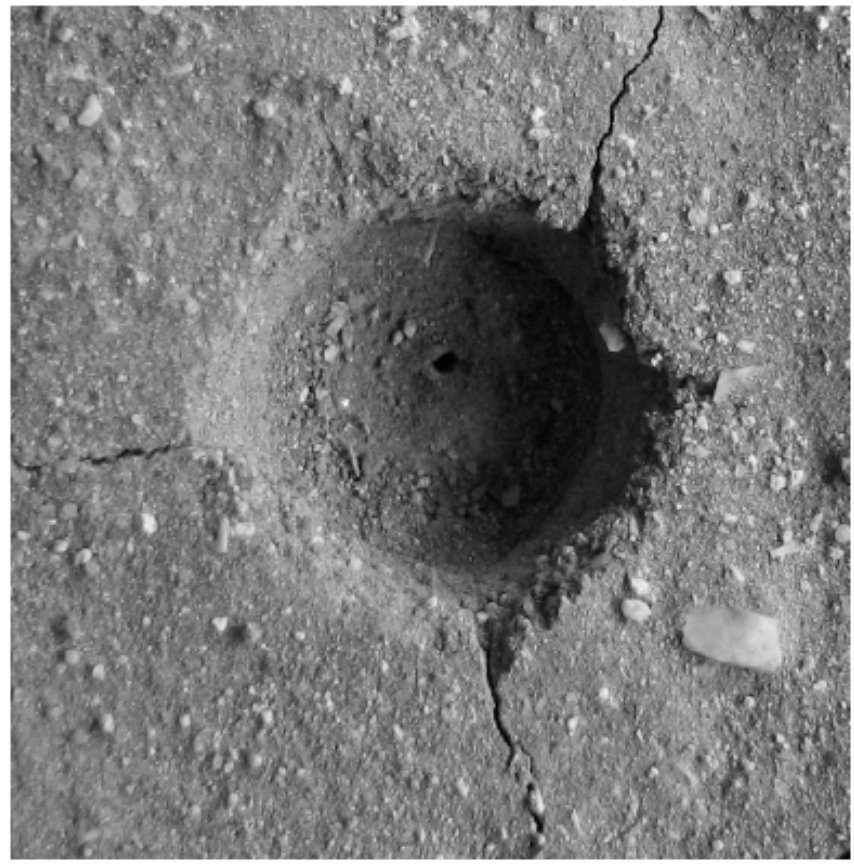

Fig. (5). Rimless circular crater in caliche over sandstone.

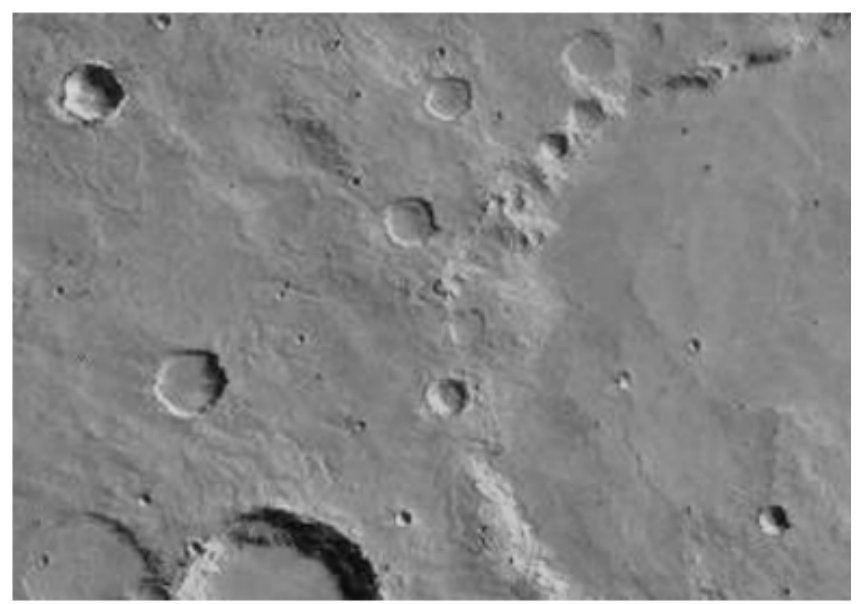

Fig. (6). NASA photo of area on Mars with rimless circular craters where some speculate that the meteorite ALH84001 originated.

speculate that the meteorite ALH84001 originated in that region [14]. The Lunar and Planetary Institute suggests that a meteorite or asteroid impact on Mars may have expelled the debris into space.

Fig. (7) depicts a rimless crater with adjacent debris. The sample is barium carbonate powder. The crater diameter is about $15 \mathrm{~mm}$ and the depth is about $5 \mathrm{~mm}$.

Fig. (8) is an image of a crater with a rim and a flat bottom. The crater diameter is about $10 \mathrm{~mm}$ and the depth about $5 \mathrm{~mm}$. The sample is aluminum hydrate powder. In the laboratory, a flat bottom is sometimes caused from the discharge impinging on a material that is harder than the main sample. There is also a tendency for the arc to rotate and cut a flat, melted floor. That might simulate the crater walls with flat terraces, seen in some large lunar craters. The crater does not always extend beyond the depth of the first level of material. 


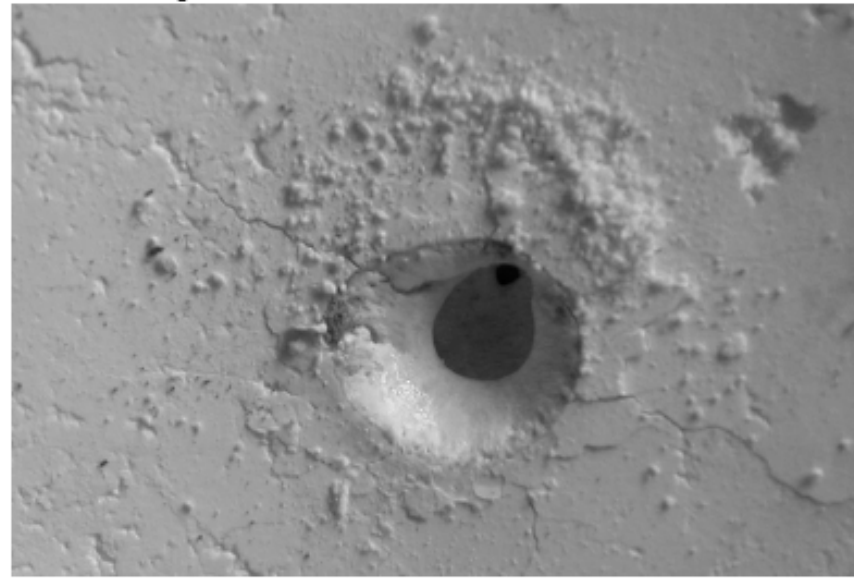

Fig. (7). Plasma-discharge generated barium carbonate powder crater with adjacent debris.

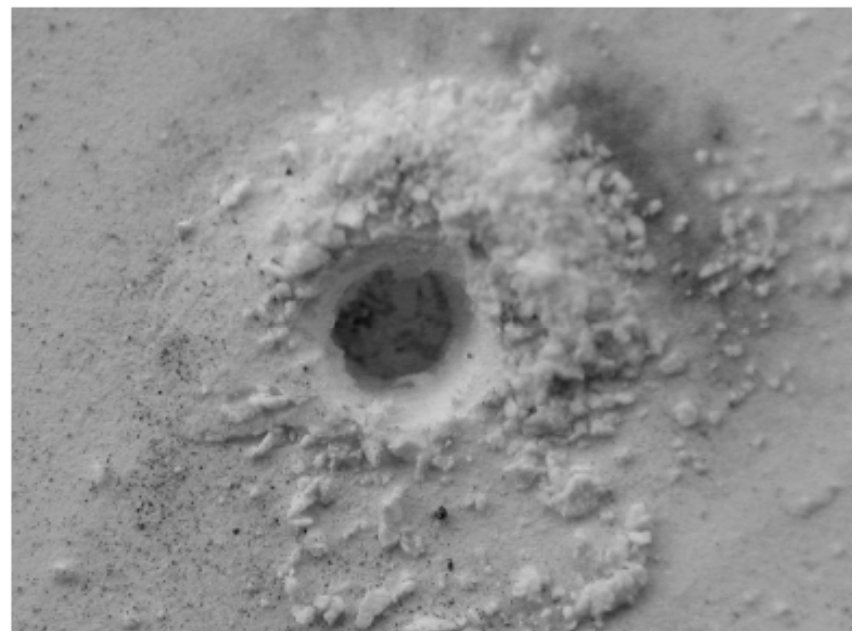

Fig. (8). Plasma discharge flat bottom crater generated in aluminum hydrate powder.



Fig. (9). Noncircular rimless crater made by plasma discharge in caliche (left), and NASA photo of noncircular crater on Moon (right).

The left side of Fig. (9) is an image of a noncircular rimless crater. This crater also has some resemblance to a canyon. The sample is dried caliche. The crater diameter is about $25 \mathrm{~mm}$ and the depth about $10 \mathrm{~mm}$. The right side of Fig. (9) is an image of a noncircular rimless crater on the Moon.

There are numerous surface features, other than single or grouped craters, found on various planets and moons. Some of those other features can also be produced by plasma discharges. For example, Peratt noted, "Voltage breakdown at
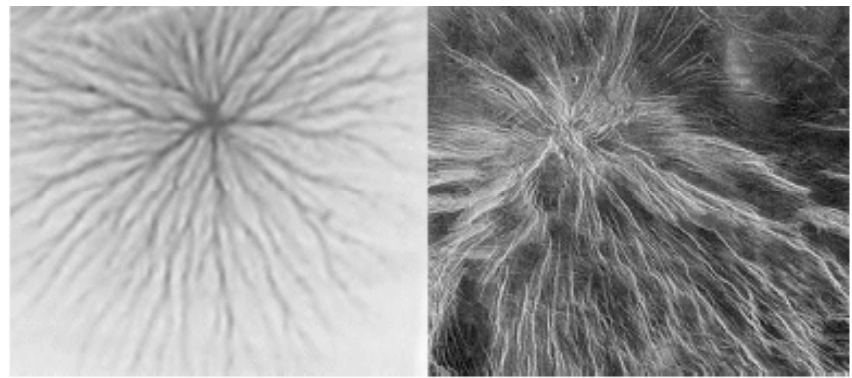

Fig. (10). Lichtenberg figure from Peratt's book (left) and NASA photo of Mokos nova (now renamed "Ts'an Nu Mons") on Venus.

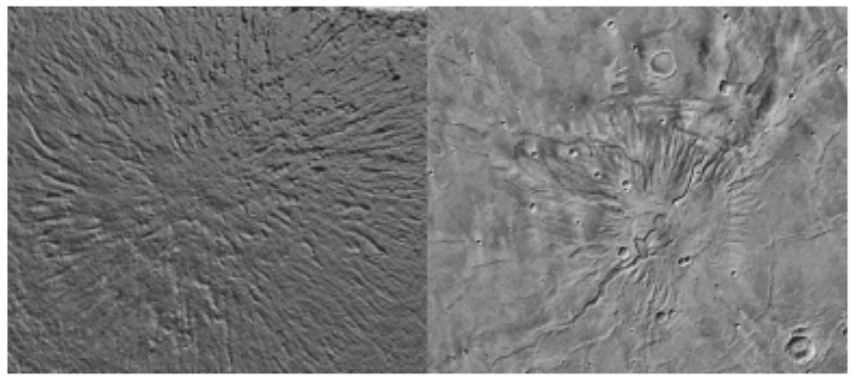

Fig. (11). Radial channels produced by plasma discharge in the lab (left) and a NASA photo showing radial channels at Tyrrhena on Mars (right).

dielectric interfaces nearly always results in the formation of the dendrite-type streamers" [15]. The left side of Fig. (10) is a Lichtenberg figure from Peratt's book Physics of the Plasma Universe. The right side of Fig. (10) is a "corona" on Venus. The Venusian corona, Mokos nova (now renamed "Ts' an $\mathrm{Nu}$ Mons"), is $250 \mathrm{~km}$ in diameter. Attempts to model Venusian coronae have employed analogs of uplift and relaxation of hot mantle diapirs. So far, they fail to model the dense radial channels observed [16].

The left side of Fig. (11) is an image from the plasma lab that shows radial channels and the right side of Fig. (11) is a NASA photo of Tyrrhena on Mars that shows radial channels. This is also similar to the Spider Radial Troughs within the Caloris Basin on Mercury. The distance across the laboratory radial area is about $60 \mathrm{~mm}$.

Fig. (12) is a picture of a multi-ringed plasma generated crater. The diameter of the smooth annulus is about $30 \mathrm{~mm}$. The depth of the large circular area inside the annulus is 1 $\mathrm{mm}$. The depth of the small circles is about $4 \mathrm{~mm}$. This multi-ring crater is similar to the multi-ring crater Orientale on the Moon. Fig. (13) is a composite of half of a crater from a plasma generated crater (left), with a radius of about 15 $\mathrm{mm}$ and depth of $1 \mathrm{~mm}$. The right side is half of Tyre on Europa. Other craters made under similar conditions resemble Valhalla on Callisto.

Craters that are large compared to the size of the body have led some to consider that Phobos and some asteroids must be porous or rubble piles [17, 18]. Plasma can generate a crater that is large compared to the size of a solid body. Fig. (14) shows a crater in an iron oxide and $20 \%$ grout body that is nearly a cylinder about $32 \mathrm{~mm}$ in diameter and $32 \mathrm{~mm}$ deep. A plasma discharge made a rimless crater about $10 \mathrm{~mm}$ in diameter and $10 \mathrm{~mm}$ deep. 


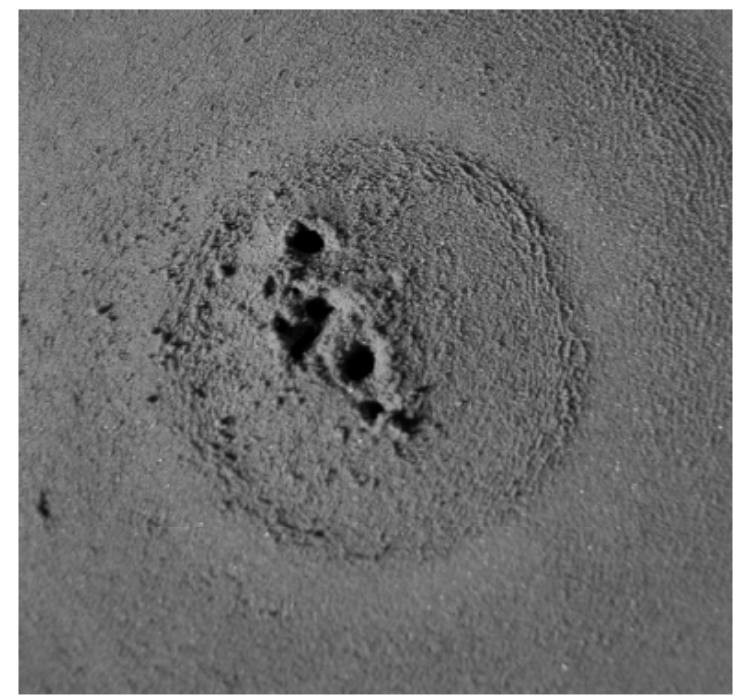

Fig. (12). Multiring crater made in the lab. The crater appearance is similar to Orientale on the Moon.

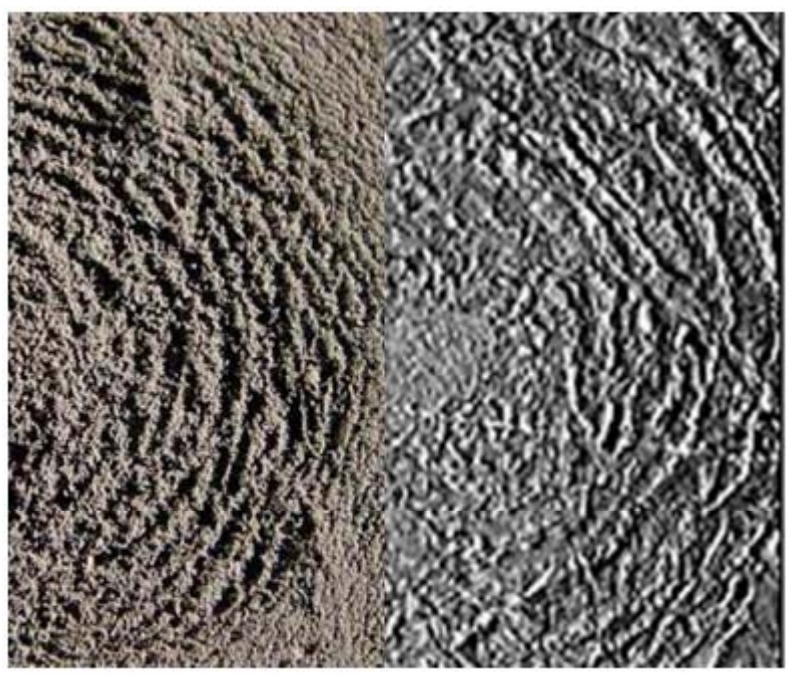

Fig. (13). Half of a plasma crater (left) and half of Tyre on Europa (right).

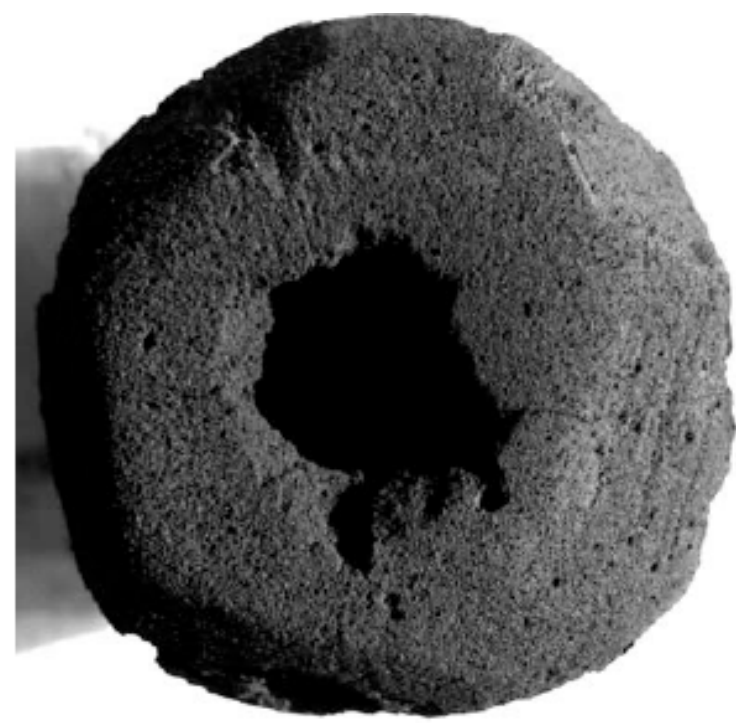

Fig. (14). Large crater compared to size of object.

\section{CONCLUSIONS}

Laboratory experiments produce plasma generated craters that are similar in appearance to those considered to be meteorite impact craters. For example, the plasma produced bowl craters, craters with radial structures, and multi-ring craters.

Plasma also produced rimless craters and craters that formed in various shapes. One type of plasma generated rimless crater featured a nearly circular outline, steep sides and a flat bottom, like rimless craters found on the Moon and Mars. The flat bottom in this case was caused by a different layer of material that was harder than the top layer. In rimless craters with sloped sides, the discharge did not always penetrate through the soft layer.

This paper extends the data for the concept of comparing plasma-discharge generated surface scars in the laboratory with surface features on solid solar system bodies. Desai's and Ford's results and these results indicate that it would be reasonable to investigate the concept further. As Desai said there is "the possibility of laboratory applications of plasma science to natural astronomical events like meteorite impact." [1] Experimental research on additional features will be the subject of other papers.

\section{ACKNOWLEDGMENT}

I thank Mel Acheson for laboratory support.

\section{CONFLICT OF INTEREST}

None Declared.

\section{REFERENCES}

[1] Desai T, Batani D, Bussoli M, et al. Laboratory craters:modeling experiments for meteorite impact craters? IEEE Trans Plasma Sci 2008; 36(4): 1132-3

[2] Ford BJ. Origin of the lunar craters. J Bri Interplanetary Soc Spaceflight 1965; 7(1): 13 .

[3] Dietz R. The moon, meteorites and comets. Solar system In: Middlehurst B, Kuiper G, Eds. Chicago USA: University of Chicago Press 1963; Vol. 4: p. 288.

[4] Alfvén H. Model of the plasma universe. IEEE Trans Plasma Sci 1986; 14(6): 629

[5] Peratt A, Snell C. Microwave generation from filamentation and vortex formation within magnetically confined electron beams. Phys Rev Lett 1985; 54: 1167

[6] Ryutov D, Remington B, Robey H, Drake R. Magnetohydrodynamic scaling: from astrophysics to the laboratory. Phys Plasmas 2001; 8(5): 1804-16.

[7] Ransom C, Thornhill W. Plasma generated spherules. Bull Am Phys Soc 2005; 50(2): 78.

[8] Ransom C, Thornhill W. Plasma-generated craters and spherules. IEEE Trans Plasma Sci 2007; 35(4): 832-1.

[9] Stewart S, Allen P. A 20-km-diameter multiringed impact structure in the North Sea. Nature 2002; 418: 520-3.

[10] Herrick R, Lyons S. Inversion of crater morphometric data to gain insight on the cratering process. Meteoritics Planetary Sci 1998; 33 131-43.

[11] Mackey F, Barlow N. Lunar and Planetary Science XXXII. Redefining the preservational categories of martian impact craters Orlando, FL: Dept. Physics, Univ. Central Florida 2001

[12] Craddock R. Modified impact craters on mars: observations, measurements and likely processes. Role of Volatiles and Atmospheres on Martian Impact Craters. Washington, DC: National Air and Space Museum: Smithsonian Institution 2005.

[13] Lohse D, Bergmann R, Mikkelsen R, et al. Impact. 2004. http://arxkat/0406368v1, PDF available from http://prl.aps.org/abstract/PRL/v93/i19/e198003 
[14] Barlow N. The search for possible source craters for Martian Meteorite ALH84001. University of Central Florida: Lunar and Planetary Science XXVIII 1997.

[15] Peratt A. Physics of the plasma universe. New York: SpringerVerlag 1992; p. 156.

[16] Krasil'nikov A, Galkin V, Basilevsky A. Tectonics and evolution of coronae on Venus: preliminary results of tectonophysical modeling. Solar Syst Res 2001; 35(2): 103-16.
[17] Housen K, Holsapple K. Impact cratering on porous asteroids. Icarus 2003; 163(1): 102-19.

[18] Bottke Jr W. Are asteroids rubble piles? Erice, Italy: $23^{\text {rd }}$ Meeting of the International Seminars on Planetary Emergencies 1998. http://www.boulder.swri.edu/ bottke/rubble/rub.html

Received: April 21, 2011

Revised: May 19, 2011

Accepted: May 19, 2011

(C) C. J. Ransom; Licensee Bentham Open.

This is an open access article licensed under the terms of the Creative Commons Attribution Non-Commercial License (http://creativecommons.org/licenses/by-nc/3.0/) which permits unrestricted, non-commercial use, distribution and reproduction in any medium, provided the work is properly cited 